\title{
ANALISIS STRUKTUR PASAR PADA PEMASARAN \\ IKAN MAS (Cyprinus carpio L) DI KELOMPOK MINA SAMPAN KAYU \\ KEC. KINTAMANI KAB. BANGLI \\ PROVINSI BALI
}

Oleh :

M. Harja Supena

Dosen Jurusan Penyuluhan Perikanan Sekolah Tinggi Perikanan

\begin{abstract}
ABSTRAK
Ikan Mas (Cyprinus carpio L) merupakan salah satu komoditas perikanan air tawar yang potensial di Kabupaten Bangli. Kabupaten Bangli terdiri dari atas 4 kecamatan yaitu Susut, Bangli, Tembuku, dan Kintamani. Berdasarkan potensi perikanan tersebut, tingkat produksi budidaya perikanan di Kabupaten Bangli terus meningkat yaitu mencapai 1.004,41 ton pada Tahun 2009. Dari jumlah produksi tersebut Ikan Mas memberikan kontribusi sebanyak 452,15 ton.

Penelitian dilakukan di Kelompok Pembudidaya "Mina Sampan Kayu” Kabupaten Bangli sebagai pasar produsen dan Pasar Sakti Mina Kabupaten Bangli sebagai pasar konsumen. Ruang lingkup penelitian difokuskan kepada Ikan Mas (Cyprinus carpio L). Data yang digunakan adalah data primer dan sekunder. Penelitian menggunakan metode deskriftif dengan jenis penelitian studi kasus. Analisis struktur pasar Ikan Mas dilakukan dengan pendekatan Structure-ConductPerformance. Penelitian bertujuan untuk mengetahui Struktur pasar Ikan Mas di Kelompok Pembudidaya "Mina Sampan Kayu” Kabupaten Bangli. Hasil penelitian menunjukkan bahwa Struktur pasar Ikan Mas di Kelompok Pembudidaya "Mina Sampan Kayu” adalah pasar persaingan tidak sempurna (imperfect competitive market) yang cenderung mengarah pada sistem pemasaran monopoli.

Bertitik tolak dari hasil penelitian tersebut, alternative solusi perbaikan sistem pemasaran Ikan Mas yang perlu dilakukan oleh Dinas Perikanan Kabupaten Bangli adalah : 1). Perbaikan infrastruktur sarana transportasi, terutama perbaikan jalan yang rusak, dan 2). Melakukan penyuluhan perikanan yang lebih intensif sehingga akan muncul kelompok-kelompok pembudidaya Ikan Mas lainnya.
\end{abstract}

Kata Kunci : Ikan Mas, Kelompok Mina Sampan Kayu, Pasar Sakti Mina, Struktur Pasar.

PENDAHULUAN

\section{Latar Belakang}

Pembangunan

merupakan salah satu bagian dari pembangunan nasional yang bertujuan antara lain untuk meningkatkan produksi dan mutu hasil perikanan, baik untuk memenuhi kebutuhan pangan dan gizi, bahan baku industri maupun ekspor hasil perikanan, sekaligus peningkatan taraf 
hidup, kesejahteraan nelayan/petani ikan melalui peningkatan pendapatannya (Raharjo, 2000). Pembangunan perikanan Indonesia saat ini bertumpu pada dua program utama. Salah satunya adalah program pengembangan budidaya ikan air tawar. Potensi usaha ikan air tawar ke depan akan semakin menggiurkan. PadaTahun 2021 konsumsi ikan perkapita penduduk dunia akan mencapai 19,6 kg per tahun, dan pada Tahun 2021 juga kebutuhan ikan air tawar akan menyentuh angka 172 juta ton per tahun yang berarti naik lebih dari 15 persen dari kebutuhan rata-rata saat ini(www.alamtani.com/ikan-air tawar.html, 2011)

Lebih dari 70 persen produksi ikan air tawar diserap oleh pasar dalam negeri. Pulau Bali merupakan salah satu penyerap terbesar mengingat pulau ini memiliki jumlah penduduk yang padat, salah satunya adalah di Kecamatan Kintamani Kabupaten Bangli.
Kecamatan ini dinilai oleh pusat (Kementrian Kelautan dan Perikanan) memiliki potensi pengembangan perikanan, khususnya dalam pembesaran Ikan Mas (Cyprinus carpio L), sehingga dijadikan kawasan pengembangan Minapolitan untuk Tahun 2011. Adapun hasil usaha pembesaran Ikan Mas ini dipasarkan di Kecamatan Kintamani khususnya di Kelompok Pembudidaya "Mina Sampan Kayu” dan para pembeli diantaranya pedagang pengumpul mendatangi langsung ke tempat usaha pembesaran tersebut.

Melihat kondisi di atas, maka Kabupaten Bangli merupakan salah satu wilayah di Indonesia khususnya di Provinsi Bali yang memiliki potensi di sektor perikanan khususnya ikan air tawar. Potensi tersebut terlihat dari produksi pada Tahun 2009 dan proyeksi luas budidaya di Kab.Bangli Tahun 2010-2014 seperti tergambar pada Tabel 1 dan 2.

Tabel 1. Rincian Produksi Perikanan Budidaya Tahun 2009

\begin{tabular}{|c|c|c|c|c|c|c|c|}
\hline \multirow[b]{2}{*}{ No } & \multirow[b]{2}{*}{ Uraian } & \multirow{2}{*}{$\begin{array}{l}\text { Jumlah } \\
\text { (ton) }\end{array}$} & \multicolumn{4}{|c|}{ Produksi (ton) } & \multirow[b]{2}{*}{ Ket } \\
\hline & & & Kolam & KJA & Sawah & Salir & \\
\hline 1. & Ikan Mas & 452,15 & 30,5 & 390 & 29,1 & 3 & Kec. Kintamani \\
\hline 2. & Nila & 512,2 & 39,8 & 460 & 10,4 & 2 & $\begin{array}{l}\text { Kec. Kintamani } \\
\text {,Bangli, Susut, dan } \\
\text { Tembuku }\end{array}$ \\
\hline 3. & Karper & 21,67 & 10,46 & 0 & 6,11 & 5,1 & $\begin{array}{l}\text { Kec. Bangli dan } \\
\text { Susut }\end{array}$ \\
\hline 4. & Lele & 5,15 & 5,15 & 0 & 0 & 0 & $\begin{array}{l}\text { Kec. Susut dan } \\
\text { Tembuku }\end{array}$ \\
\hline 5. & Ikan lainnya & 13,24 & 11,34 & 0 & 0 & 1,9 & $\begin{array}{l}\text { Kec. Bangli, } \\
\text { Susut,dan Tem- } \\
\text { Buku }\end{array}$ \\
\hline & JUMLAH .... = & $1.004,41$ & 97,25 & 850 & 45,61 & 12 & \\
\hline
\end{tabular}

Sumber : Dinas Perikanan dan Peternakan Kab. Bangli, 2012 
Tabel 2. Proyeksi Luas Budidaya/Penangkapan Ikan di Perairan Umum di Kab. Bangli Tahun 2010-2014

\begin{tabular}{|c|c|c|c|c|c|c|c|}
\hline \multirow{2}{*}{ No } & \multirow{2}{*}{ Uraian } & \multicolumn{5}{|c|}{ Sasaran Luas (Ha) } & \multirow{2}{*}{$\begin{array}{c}\text { Ket } \\
\text { Peningkatan }\end{array}$} \\
\hline & & 2010 & 2011 & 2012 & 2013 & 2014 & \\
\hline 1 & 2 & 3 & 4 & 5 & 6 & 7 & 8 \\
\hline A & BD. IKAN & 201,44 & 205,86 & 213,90 & 222,65 & 234,78 & 7,64 \\
\hline 1. & $\begin{array}{l}\text { Sawah : } \\
\text { - Inmindi } \\
\text { - Non Inmindi }\end{array}$ & $\begin{array}{r}\mathbf{1 8 1 , 0 0} \\
85,00 \\
96,00\end{array}$ & $\begin{array}{r}\mathbf{1 8 3 , 0 0} \\
86,00 \\
97,00\end{array}$ & $\begin{array}{r}\mathbf{1 8 5 , 0 0} \\
87,00 \\
98,00\end{array}$ & $\begin{array}{r}\mathbf{1 8 7 , 0 0} \\
88,00 \\
99,00\end{array}$ & $\begin{array}{r}\mathbf{1 8 9 , 0 0} \\
89,00 \\
100,00\end{array}$ & $\begin{array}{l}2,16 \\
2,30 \\
2,04\end{array}$ \\
\hline 2. & Kolam & 15,40 & 16,10 & 20,80 & 26,00 & 35,10 & 39,01 \\
\hline 3. & $\begin{array}{l}\text { Per. Umum : } \\
\text { - Sal. Irigasi } \\
\text { - Jaka/Karamba }\end{array}$ & $\begin{array}{l}5,04 \\
3,51 \\
1,53\end{array}$ & $\begin{array}{l}\mathbf{6 , 7 6} \\
3,71 \\
3,05\end{array}$ & $\begin{array}{l}\mathbf{8 , 1 0} \\
4,05 \\
4,05\end{array}$ & $\begin{array}{l}9,65 \\
4,40 \\
5,25\end{array}$ & $\begin{array}{r}10,68 \\
4,73 \\
5,95\end{array}$ & $\begin{array}{l}35,88 \\
14,81 \\
59,09\end{array}$ \\
\hline B & Penangkapan I & $1.639,90$ & $1.639,90$ & $1.639,90$ & $1.639,90$ & $1.639,90$ & - \\
\hline $\begin{array}{l}1 . \\
2 . \\
3 .\end{array}$ & $\begin{array}{l}\text { Sungai } \\
\text { Waduk } \\
\text { Danau }\end{array}$ & $\begin{array}{r}30,00 \\
2,40 \\
1.607,50\end{array}$ & $\begin{array}{r}30,00 \\
2,40 \\
1.607,50\end{array}$ & $\begin{array}{r}30,00 \\
2,40 \\
1.607,50\end{array}$ & $\begin{array}{r}30,00 \\
2,40 \\
1.607,50\end{array}$ & $\begin{array}{r}30,00 \\
2,40 \\
1.607,50\end{array}$ & $\begin{array}{l}- \\
- \\
-\end{array}$ \\
\hline & JUMLAH .... = & $1.841,34$ & $1.845,76$ & $1.853,80$ & $1.862,55$ & $1.874,68$ & 0,34 \\
\hline
\end{tabular}

Sumber : Dinas Perikanan dan Peternakan Kab. Bangli, 2012

Masalah umum yang terjadi adalah jauhnya jarak antara Kecamatan Kintamani dengan Ibu Kota Kabupaten Bangli yakni mencapai kurang lebih 60 km dengan kondisi prasarana jalan hanya 50 \% beraspal. Padahal menurut Anwar (1995), bahwa lokasi yang tersebar dan berjauhan, menyebabkan pasar kompetitif tidak dapat terwujud (missing market). Selain itu, kondisi seperti ini akan mudah dimanfaatkan pedagang untuk mencari keuntungan yang lebih besar, terutama dalam pembentukan harga di tingkat produsen.

\section{Rumusan Masalah}

Bagaimana struktur pasar yang terjadi di Kelompok Pembudidaya "Mina Sampan Kayu” Desa Kedisan Kec. Kintamani, Kab. Bangli, Prov.Bali?

\section{Tujuan Penelitian}

Mengetahui struktur pasar yang terjadi di Kelompok Pembudidaya "Mina Sampan Kayu” Desa Kedisan Kec. Kintamani, Kab. Bangli, Prov.Bali

\section{METODE PENELITIAN}

\section{Lokasi dan Waktu}

Penelitian akan dilakukan di Pasar Kelompok Pembudidaya Mina Sampan Kayu (MSK) Desa Kedisan Kec. Kintamani Kabupaten Bangli Provinsi Bali pada Bulan Juni - Juli 2011. Untuk lebih jelasnya lokasi penelitian dapat dilihat pada 


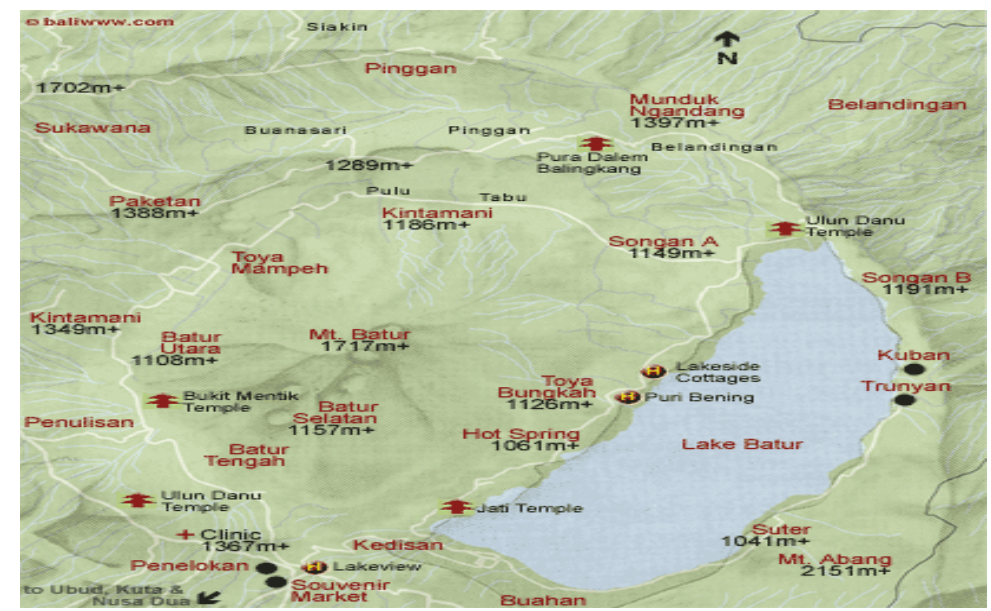

Gambar 1. Peta Kecamatan Kintamani

\section{Pendekatan Penelitian}

Penelitian menggunakan metode deskriptif dengan jenis penelitian studi kasus.

\section{Jenis dan Sumber Data}

Data yang dikumpulkan dalam penelitian ini adalah data primer dan data sekunder. Data primer diperoleh dari petani/pembudidaya dan pedagang melalui wawancara kepada para pelaku pemasaran. Data primer yang dikumpulkan terdiri atas "data identitas” dan "data usaha” baik untuk petani/pembudidaya maupun untuk pedagang, yang meliputi :

I. Data identitas : nomor responden, nama, umur, jenis kelamin, tingkat pendidikan.

II. Data usaha : Jenis Usaha, status kepemilikan, Orientasi Usaha, tempat pelihara/budidaya, jenis komoditi, tenaga kerja, hasil produksi, pembelian, penjualan.

Sedangkan data sekunder di peroleh dari Dinas Perikanan dan Peternakan Kab. Bangli, BPS Kabupaten Bangli, Perpustakaan dan internet.

\section{Teknik Pengambilan Contoh}

Teknik pengambilan contoh yang digunakan adalah Purposive Sampling, yaitu peneliti secara sengaja memilih atau menentukan serta mewawancarai 10 orang petani/pembudidaya Ikan Mas dan 10 orang pedagang yang terdiri atas pedagang pengumpul dan pedagang pengecer Ikan Mas .

\section{Teknik Pengolahan dan Analisa Data}

Data dan informasi yang dikumpulkan dianalisis dengan menggunakan pendekatan kuantitatif dan kualitatif. Pendekatan kuantitatif dilakukan jika ciri-ciri dari suatu fakta sosial dapat dinilai dengan angka-angka. Sedangkan pendekatan kualitatif dilakukan jika ciri-ciri dari suatu fakta sosial tidak dapat diutarakan dalam angka-angka, tetapi dalam bentuk kategori-kategori (Koentjoroningrat, 1993).

\section{HASIL DAN PEMBAHASAN}

\section{Karakteristik Petani/Pembudidaya Ikan Mas \\ Jumlah responden yang terpilih dalam penelitian ini adalah 10 orang petani/pembudidaya Ikan Mas . Hasil}


wawancara disajikan dalam bentuk tabulasi seperti tertuang dalam Tabel 3.

Tabel 3. Hasil Penelitian Karakteristik Pembudidaya Ikan Mas di Kelompok Pembudidaya "Mina Sampan Kayu” Ds. Kedisan Kec. Kintamani Kab. Bangli

\begin{tabular}{|c|c|c|c|c|}
\hline No & $\begin{array}{c}\text { Karakteristik } \\
\text { Petani/Pembudidaya }\end{array}$ & Variabel Penelitian & $\begin{array}{c}\text { Jumlah } \\
\text { Responden } \\
\text { (org) }\end{array}$ & Prosentase (\%) \\
\hline 1. & Umur & $\begin{array}{l}\text { a. } 20-25 \text { tahun } \\
\text { b. } 26-35 \text { tahun } \\
\text { c. } 36-50 \text { tahun } \\
\text { d. } \quad>50 \text { tahun }\end{array}$ & $\begin{array}{l}3 \\
3 \\
4 \\
-\end{array}$ & $\begin{array}{c}30 \\
30 \\
40 \\
-\end{array}$ \\
\hline 2. & Jenis Kelamin & \begin{tabular}{|ll} 
a. & Laki-laki \\
b. & Perempuan
\end{tabular} & $\begin{array}{c}10 \\
-\end{array}$ & $\begin{array}{c}100 \\
-\end{array}$ \\
\hline 3. & Tk. Pendidikan & $\begin{array}{ll}\text { a. } & \text { Tdk.pernah ekolah } \\
\text { b. } & \text { SD } \\
\text { c. } & \text { SLTP } \\
\text { d. } & \text { SLTA } \\
\text { e. } & \text { Perguruan Tinggi }\end{array}$ & $\begin{array}{l}- \\
2 \\
2 \\
6 \\
-\end{array}$ & $\begin{array}{c}- \\
20 \\
20 \\
60 \\
-\end{array}$ \\
\hline 4. & Jenis Usaha & $\begin{array}{ll}\text { a. } & \text { Pembenih } \\
\text { b. Pembesar } \\
\text { c. Pembenih \& Pembesar }\end{array}$ & $\begin{array}{l}- \\
10 \\
-\end{array}$ & $\begin{array}{c}- \\
100 \\
-\end{array}$ \\
\hline 5. & Orientasi Usaha & $\begin{array}{ll}\text { a. Usaha Pokok } \\
\text { b. Usaha Sampingan }\end{array}$ & $\begin{array}{c}10 \\
- \\
\end{array}$ & $\begin{array}{c}100 \\
- \\
\end{array}$ \\
\hline 6. & $\begin{array}{l}\text { Jenis Ikan yang } \\
\text { Dipelihara/Budidaya }\end{array}$ & $\begin{array}{l}\text { a. Nila } \\
\text { p. Mas } \\
\text { c. Kedua-duanya }\end{array}$ & $\begin{array}{c}- \\
10 \\
-\end{array}$ & $\begin{array}{c}- \\
100 \\
-\end{array}$ \\
\hline 7. & $\begin{array}{l}\text { Hasil Produksi Setiap } \\
\text { Periode ( } 5-6 \text { bulan) }\end{array}$ & $\begin{array}{l}\text { a. } \quad<50 \mathrm{~kg} \\
\text { b. } \quad 51-100 \mathrm{~kg} \\
\text { c. } 101-500 \mathrm{~kg} \\
\text { d. }>500 \mathrm{~kg}\end{array}$ & $\begin{array}{l}- \\
- \\
- \\
10\end{array}$ & $\begin{array}{c}- \\
- \\
- \\
100\end{array}$ \\
\hline 8. & $\begin{array}{l}\text { Sistem Penjualan Ikan } \\
\text { Mas }\end{array}$ & $\begin{array}{ll}\text { a. Langsung di lokasi } \\
\text { kelompok } \\
\text { b. Melalui pasar } \\
\text { c. Melalui keduanya } \\
\text { d. Melalui cara lain } \\
\end{array}$ & $\begin{array}{l}10 \\
- \\
- \\
-\end{array}$ & $\begin{array}{l}100 \\
- \\
- \\
-\end{array}$ \\
\hline 9. & $\begin{array}{l}\text { Harga Penjualan Ikan } \\
\text { Mas di Lokasi } \\
\text { Kelompok }\end{array}$ & $\begin{array}{l}\text { a. Lebih baik dibanding } \\
\text { lainnya. } \\
\text { b. Relatif sama } \\
\text { c. Lebih rendah } \\
\text { d. Tidak tentu } \\
\end{array}$ & $\begin{array}{l}10 \\
- \\
- \\
-\end{array}$ & $\begin{array}{l}100 \\
- \\
- \\
-\end{array}$ \\
\hline 10. & $\begin{array}{l}\text { Cara Memperoleh } \\
\text { Informasi Harga }\end{array}$ & $\begin{array}{l}\text { a. Kelompok Petani } \\
\text { /Pembudidaya } \\
\text { b. Pedagang } \\
\text { c.Teman/Keluarga/Se-sama } \\
\text { Pembudidaya } \\
\text { d. Lain-lain (a dan b) } \\
\end{array}$ & $\begin{array}{l}3 \\
- \\
2 \\
5 \\
-\end{array}$ & $\begin{array}{c}30 \\
- \\
20 \\
50 \\
-\end{array}$ \\
\hline
\end{tabular}

Sumber : Data Primer, 2012

\section{Karakteristik Pedagang Ikan Mas}

Jumlah responden yang terpilih dalam penelitian ini adalah 10 orang responden yang menjual Ikan Mas, terdiri atas : 5 orang Pedagang Pengumpul Lokal/Supplier dan 5 orang Pedagang Pengecer. Hasil wawancara disajikan dalam bentuk tabulasi seperti tertuang dalam Tabel 4. 
Tabel 4. Hasil Penelitian Karakteristik Pedagang Ikan Mas di Kelompok Pembudidaya "Mina Sampan Kayu” Ds. Kedisan Kec. Kintamani Kab. Bangli

\begin{tabular}{|c|c|c|c|c|}
\hline No & $\begin{array}{c}\text { Karakteristik } \\
\text { Pedagang }\end{array}$ & Variabel Penelitian & $\begin{array}{c}\text { Jumlah } \\
\text { Responden } \\
\text { (org) }\end{array}$ & Prosentase (\%) \\
\hline 1. & Umur & $\begin{array}{l}\text { a. } 20-25 \text { tahun } \\
\text { b. 26-35 tahun } \\
\text { c. } 36-50 \text { tahun } \\
\text { d. } \quad>50 \text { tahun }\end{array}$ & $\begin{array}{l}2 \\
3 \\
4 \\
1\end{array}$ & $\begin{array}{l}20 \\
30 \\
40 \\
10\end{array}$ \\
\hline 2. & Jenis Kelamin & \begin{tabular}{|ll} 
a. & Laki-laki \\
b. & Perempuan
\end{tabular} & $\begin{array}{l}10 \\
-\end{array}$ & 100 \\
\hline 3. & Tk. Pendidikan & $\begin{array}{ll}\text { a. } & \text { Tdk.pernah sekolah } \\
\text { b. } & \text { SD } \\
\text { c. } & \text { SLTP } \\
\text { d. } & \text { SLTA } \\
\text { e. } & \text { Perguruan Tinggi }\end{array}$ & $\begin{array}{l}- \\
- \\
3 \\
7 \\
-\end{array}$ & $\begin{array}{c}- \\
- \\
30 \\
70 \\
-\end{array}$ \\
\hline 4. & Bentuk Usaha & $\begin{array}{ll}\text { a. } & \text { Perorangan } \\
\text { b. } & \text { Badan Usaha }\end{array}$ & 10 & $\begin{array}{c}100 \\
-\end{array}$ \\
\hline 5. & Status Usaha & $\begin{array}{ll}\text { a. } & \text { Ped. Pengumpul } \\
& \text { lokal/Supplier } \\
\text { b. } & \text { Ped.Besar/Eksportir } \\
\text { c. } & \text { Ped. Pengecer }\end{array}$ & $\begin{array}{l}5 \\
- \\
5\end{array}$ & $\begin{array}{l}50 \\
- \\
50\end{array}$ \\
\hline 6. & Orientasi Usaha & $\begin{array}{ll}\text { a. } & \text { Usaha Pokok } \\
\text { b. } & \text { Usaha Sampingan } \\
\end{array}$ & 10 & $\begin{array}{c}100 \\
- \\
\end{array}$ \\
\hline 7. & Volume Pembelian & 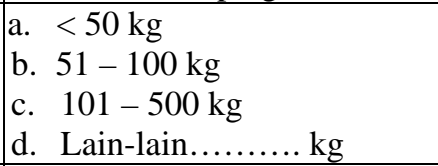 & $\begin{array}{l}5 \\
3 \\
2 \\
-\end{array}$ & $\begin{array}{l}50 \\
30 \\
20 \\
- \\
\end{array}$ \\
\hline 8. & Harga Pembelian & $\begin{array}{ll}\text { a. } & \text { Rp. } 5.000-\text { Rp.10.000 } \\
\text { b. } & \text { Rp.10.500- Rp.15.000 } \\
\text { c. } & \text { Rp.15.500- Rp. } 20.000 \\
\text { d. } & \text { Rp.20.500- Rp. } 25.000\end{array}$ & $\begin{array}{c}- \\
10 \\
- \\
-\end{array}$ & $\begin{array}{c}- \\
100 \\
- \\
-\end{array}$ \\
\hline 9. & $\begin{array}{l}\text { Sumber Ikan Mas Yg } \\
\text { dibeli }\end{array}$ & $\begin{array}{lll}\text { a. } & \text { Kelompok Petani } \\
& \text { Pembudidaya } & \\
\text { b. } & \text { Ped.Pengumpul } & \text { Lokal } \\
& \text { /Supplier } \\
\text { c. } & \text { Ped.Besar/Eksportir } \\
\text { d. } & \text { Ped. Pengecer } & \\
\text { e. } & \text { Lain-lain (Petani) } & \end{array}$ & $\begin{array}{l}1 \\
9 \\
- \\
- \\
-\end{array}$ & $\begin{array}{l}10 \\
90 \\
- \\
- \\
-\end{array}$ \\
\hline 10. & $\begin{array}{l}\text { Harga Penjualan Ikan } \\
\text { Mas }\end{array}$ & \begin{tabular}{|ll} 
a. & Rp. $5.000-$ Rp. 10.000 \\
b. & Rp.10.500- Rp.15.000 \\
c. & Rp.15.500- Rp. 20.000 \\
d. & Rp.20.500- Rp.25.000 \\
\end{tabular} & $\begin{array}{c}- \\
- \\
10 \\
-\end{array}$ & $\begin{array}{l}- \\
- \\
100 \\
- \\
\end{array}$ \\
\hline 11. & $\begin{array}{l}\text { Cara Memperoleh } \\
\text { Informasi Harga }\end{array}$ & 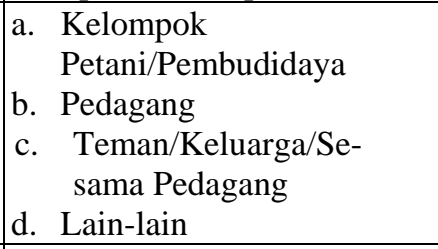 & $\begin{array}{l}6 \\
2 \\
2 \\
-\end{array}$ & $\begin{array}{l}60 \\
20 \\
20 \\
-\end{array}$ \\
\hline 12. & $\begin{array}{l}\text { Sistem Penjualan Ikan } \\
\text { Mas }\end{array}$ & \begin{tabular}{|llr} 
a. & $\begin{array}{l}\text { Ped. Bebas } \\
\\
\text { pembeli }\end{array}$ & memilih \\
b. & Ped.terikat & dengan \\
& pembeli & \\
c. & Langganan & (customer \\
& loyal) & \\
d. & Lain-lain &
\end{tabular} & $\begin{array}{r}- \\
- \\
- \\
-\end{array}$ & $\begin{array}{l}- \\
- \\
-\end{array}$ \\
\hline
\end{tabular}

Sumber : Data Primer, 2012 


\section{Analisis Struktur Pasar}

Struktur pasar Ikan Mas yang ada di daerah penelitian dianalisis berdasarkan beberapa faktor diantaranya adalah Lembaga dan saluran pemasaran (Kotler dan Amstrong. 1992.)

\section{Lembaga dan Saluran Pemasaran}

Lembaga pemasaran yang terlibat dalam pemasaran Ikan meliputi: pembudidaya, pedagang pengumpul tingkat I (PP I) yang berasal dari tingkat kecamatan, pedagang pengumpul tingkat II (PP II) yang berasal dari tingkat kabupaten, dan pedagang pengecer (Hanafiah dan Saefuddin. 1986).

Total 100\% penjualan (500 kg) tersebut terbagi ke dalam 3 saluran pemasaran yaitu $55 \%$ atau $275 \mathrm{~kg}$ untuk saluran pemasaran I, $30 \%$ atau $150 \mathrm{~kg}$ untuk saluran pemasaran II, dan $15 \%$ atau $75 \mathrm{~kg}$ untuk saluran pemasaran III. Adapun ketiga saluran dimaksud dapat dilihat pada Gambar 2.
(I)

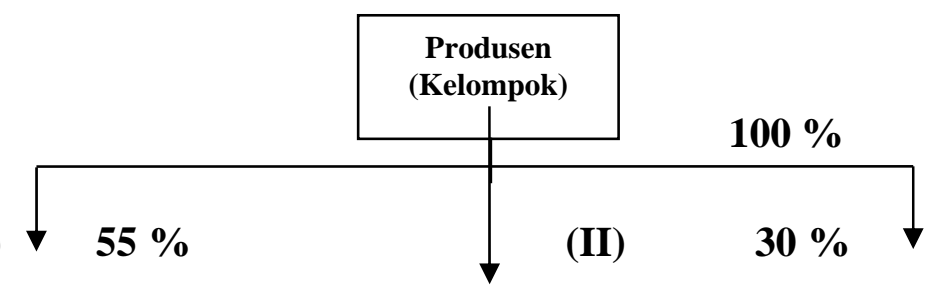

(III)

$15 \%$
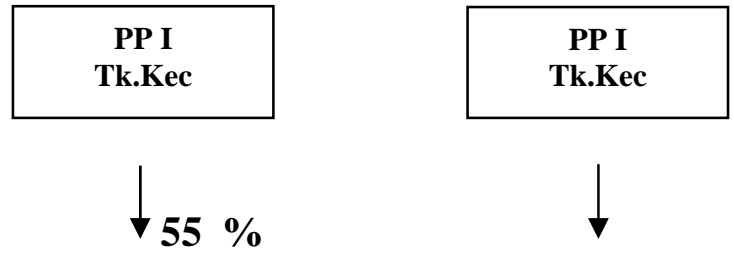

$15 \%$

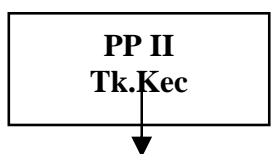

$55 \%$
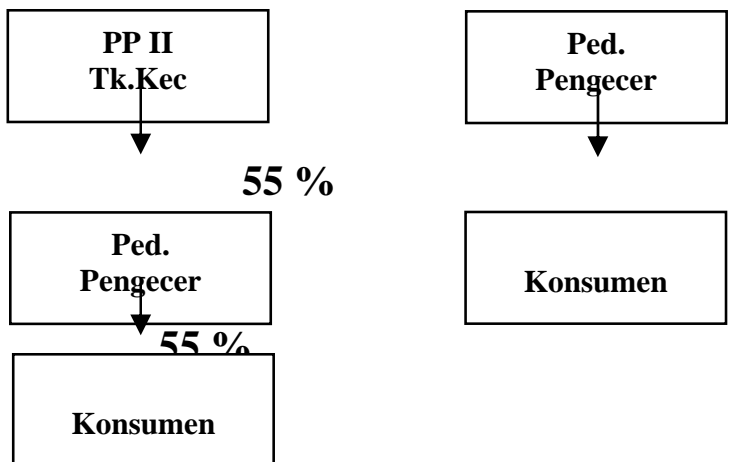

Gambar 2. Saluran Pemasaran Ikan Mas di Kelompok Pembudidaya Mina Sampan Kayu Desa Kedisan

Saluran pemasaran I :

Pedagang Pengumpul Tingkat Kecamatan merupakan pihak pertama yang melakukan kegiatan transaksi jual beli Ikan Mas sebesar 55 \% dengan pihak produsen (Kelompok Pembudidaya Mina Sampan Kayu) untuk ditampung dan dipasarkan kepada PP2 yaitu Pedagang Pengumpul di Tingkat Kabupaten maupun Pedagang Pengecer dan konsumen di kecamatan dalam hal ini adalah Kecamatan Kintamani. Di daerah Berdasarkan Gambar 2, Pedagang Pengumpul 
Tingkat I (PP I) dalam hal ini penelitian, terdapat 2 PP1 dan 1 kelompok pembudidaya yang berperan sebagai produsen/penjual yaitu Kelompok Mina Sampan Kayu, dengan demikian bila dianalisis berdasarkan jumlah pembudidaya sebagai produsen/penjual maka dapat dikatakan bahwa struktur pasar yang terbentuk adalah pasar monopoli dari sudut pembeli. Hal ini disebabkan karena jumlah PP I jauh lebih banyak bila dibandingkan dengan jumlah kelompok pembudidaya. Dengan demikian PP I menjadi pihak penerima harga (price taker) sesuai dengan harga yang telah ditetapkan oleh kelompok pembudidaya (Kotler danKeller. 2006).

Pedagang pengumpul tingkat II

(PP II) dalam hal ini Pedagang Pengumpul Tingkat Kabupaten merupakan rantai pemasaran selanjutnya setelah produk melalui PP I. Terdapat 5 orang PP II, dengan demikian bila ditinjau dari sudut pembeli, maka struktur pasar yang terbentuk adalah oligopoli. Hal ini disebabkan karena ada beberapa PP I yang berperan sebagai penjual. Pada strata ini PP II cenderung menjadi pihak penerima harga (price taker) sesuai dengan harga yang telah ditetapkan oleh PP I.

Pedagang pengecer merupakan rantai pemasaran selanjutnya setelah produk melalui PP II. Di Pasar Ikan Sakti Mina Kabupaten Bangli, yang merupakan pasar konsumen terdapat 6 orang pedagang pengecer yang menjual Ikan Mas . Bila ditinjau dari sudut pembeli, maka struktur pasar yang terbentuk adalah Pasar Oligopsoni. Hal ini disebabkan karena jumlah PP II sama banyak jumlahnya dengan pedagang pengecer. Pada strata ini pedagang pengecer cenderung menjadi pihak penerima harga (price taker) sesuai dengan harga yang telah ditetapkan oleh PP II.

Saluran pemasaran II :

Pada Saluran Pemasaran II, terdapat 2 orang PP 1 yang melakukan kegiatan transaksi jual beli Ikan Mas namun hanya sebesar $30 \%$. Dengan demikian bila dianalisis berdasarkan jumlah pembudidaya sebagai produsen/penjual maka dapat dikatakan bahwa struktur pasar yang terbentuk adalah pasar monopoli dari sudut pembeli. Hal ini disebabkan karena jumlah PP I jauh lebih banyak bila dibandingkan dengan jumlah kelompok pembudidaya. Dengan demikian PP I menjadi pihak penerima harga (price taker) sesuai dengan harga yang telah ditetapkan oleh kelompok pembudidaya.

Pedagang pengecer merupakan rantai pemasaran selanjutnya setelah produk melalui PP I. Di Kecamatan Kintamani terdapat 3 orang pedagang pengecer yang menjual Ikan Mas . Bila ditinjau dari sudut pembeli, maka struktur pasar yang terbentuk adalah Pasar Duopoli (Simatupang dan Situmorang. 1988). Hal ini disebabkan karena jumlah PP I hanya ada dan lebih sedikit jumlahnya dibandingkan dengan pedagang pengecer. Pada strata ini pedagang pengecer cenderung menjadi pihak penerima harga (price taker) sesuai dengan harga yang telah ditetapkan oleh PP I.

Saluran pemasaran III :

Pada Saluran Pemasaran III, hanya terdapat 2 orang Pedagang Pengecer yang melakukan kegiatan transaksi jual beli Ikan Mas namun hanya sebesar $15 \%$. Dengan demikian 
bila dianalisis berdasarkan jumlah pembudidaya sebagai produsen/penjual maka dapat dikatakan bahwa struktur pasar yang terbentuk adalah pasar monopoli dari sudut pembeli. Hal ini disebabkan karena jumlah Pedagang Pengecer jauh lebih banyak bila dibandingkan dengan jumlah kelompok pembudidaya. Dengan demikian Pedagang Pengecer menjadi pihak penerima harga (price taker) sesuai dengan harga yang telah ditetapkan oleh kelompok pembudidaya.

Menurut Hasibuan

(1993),

konfigurasi pasar seperti itu, maka struktur pasar Ikan Mas yang ada di kelompok pembudidaya Mina Kayu Sampan adalah pasar persaingan tidak sempurna (imperfect competitive market).

\section{KESIMPULAN DAN SARAN}

\section{Kesimpulan}

Strukur pasar yang berlaku di Kelompok Pembudidaya Ikan Mas Mina Sampan Kayu di Desa Kedisan Kecamatan Kintamani Kabupaten Bangli adalah pasar persaingan tidak sempurna (imperfectly competition market). Dengan struktur pasar tersebut, maka perilaku pasar yang terjadi adalah kuatnya daya tawar (bargaining position) kelompok pembudidaya Ikan Mas dalam penentuan/penetapan harga, dan adanya dominasi informasi pasar yang merupakan salah satu bentuk strategi dalam menjaga stabilitas pasar.

\section{Saran}

Berdasarkan kesimpulan di atas, disebutkan bahwa struktur pasar yang terjadi di Kelompok Pembudidaya Ikan Mas Mina Sampan Kayu di Desa
Kedisan Kecamatan Kintamani

Kabupaten Bangli adalah pasar persaingan tidak sempurna (imperfectly competition market) yang lebih mengarah kepada Struktur Pasar Monopoli. Atas dasar tersebut disarankan kepada pihak pemerintah setempat khususnya Dinas Perikanan Kabupaten Bangli agar melakukan penyuluhan perikanan yang lebih intensif lagi sehingga akan muncul kelompok-kelompok pembudidaya Ikan Mas lainnya.

\section{DAFTAR PUSTAKA}

Anwar, A. 1995. Beberapa Proposisi Kelembagaan Agribisnis di Pedesaan. Mimbar Sosek, Institut Pertanian Bogor. (1): 58-64.

Hanafiah, A.M. dan A.M. Saefuddin. 1986. Tataniaga Hasil Perikanan. UI Press, Jakarta.

Hasibuan, N. 1993. Ekonomi Industri (Persaingan, Monopoli dan Regulasi). LP3ES, Jakarta. t. 1993. Metode Penelitian Masyarakat. Gramedia Pustaka Utama, Jakarta.

Kotler. P dan G. Amstrong. 1992. Dasardasar Pemasaran (Jilid I Edisi 5). Intermedia, Jakarta.

Kotler. P dan K.L. Keller. 2006. Manajemen Pemasaran (Jilid 1 Edisi 12). Indeks, Jakarta.

Raharjo,M. 2000. Strategi Peningkatan Mutu Produk Hasil Perikanan Jurnal Agroekonomi, 67 (1) 1-11. 